Check for updates

Cite this: RSC Adv., 2017, 7, 36450

Received 15th June 2017

Accepted 15th July 2017

DOI: 10.1039/c7ra06691k

rsc.li/rsc-advances

\section{Highly thermally conductive and electrically insulating polymer nanocomposites with boron nitride nanosheet/ionic liquid complexes $\uparrow$}

\begin{abstract}
Takuya Morishita (iD * and Naoko Takahashi
Highly thermally conductive and electrically insulating polymer materials are eagerly anticipated for thermal management of various applications including next-generation power electronic devices. Herein, boron nitride nanosheet (BNNS)/ionic liquid (IL)/polymer composites with high thermal conductivity (TC) and high electrical insulation were fabricated. BNNSs were exfoliated and noncovalently functionalized with ILs by one-step route using liquid-phase exfoliation of hexagonal boron nitrides in ILs. ILs improved exfoliation by physical adsorption on BNNS surfaces, forming highly soluble few-layered BNNS/IL complexes with high yields. The use of 1-butyl-3-methylimidazolium hexafluorophosphate ([bmim] $\left[\mathrm{PF}_{6}\right]$ ) gave sufficient amounts of BNNS/[bmim] $\left[\mathrm{PF}_{6}\right]$ complexes for fabrication of BNNS/IL/polymer composites. Then BNNS/[bmim] $\left[\mathrm{PF}_{6}\right] /$ poly(methyl methacrylate) (PMMA) composite films were prepared using a simple wet-process, significantly enhancing both through-plane and in-plane TCs. The throughplane and in-plane TCs of the BNNS/[bmim] $\left[\mathrm{PF}_{6}\right] / \mathrm{PMMA}$ composite films containing 50 wt\% ( $\approx 34$ vol\%) BNNS reached approx. $5.4 \mathrm{~W} \mathrm{~m}^{-1} \mathrm{~K}^{-1}$ and approx. $7.3 \mathrm{~W} \mathrm{~m}^{-1} \mathrm{~K}^{-1}$, respectively. The through-plane TC is superior to those of previously reported BNNS/thermoplastic (TP) polymer composites with similar BNNS loadings. This high through-plane TC derives from randomly dispersed BNNSs and good affinity between $\mathrm{PMMA}$ and $[\mathrm{bmim}]\left[\mathrm{PF}_{6}\right]$ on the BNNS surface. The optimum functionalization ratio (FR, [bmim] $\left[\mathrm{PF}_{6}\right] / \mathrm{BNNS}$ mass ratio) found for enhancing the TC represents a balance of increased compatibility of BNNS/PMMA and a decrease of $\mathrm{TC}$ caused by extra amorphous $\left[\mathrm{bmim}\left[\mathrm{PF}_{6}\right]\right.$. Furthermore, the combination of IL and polymer matrix species is important. The through-plane TC of BNNS/[bmim] $\left[\mathrm{PF}_{6}\right] /$ polybutylene terephthalate (PBT) composite films containing $50 \mathrm{wt} \%$ BNNS was extremely high (approx. $5.8 \mathrm{~W} \mathrm{~m}^{-1}$ $\mathrm{K}^{-1}$ ), although that of $B N N S /\left[b_{m i m}\right]\left[\mathrm{PF}_{6}\right] /$ polycarbonate $(\mathrm{PC})$ composite films was very low (approx. $1.2 \mathrm{~W} \mathrm{~m}^{-1} \mathrm{~K}^{-1}$ ) because of the lower affinity of $\left[\mathrm{bmim}\left[\mathrm{PF}_{6}\right]\right.$ with $\mathrm{PC}$. Moreover, the volume resistivity of the BNNS/[bmim] $\left[\mathrm{PF}_{6}\right] / \mathrm{TP}$ polymer composites was improved compared with that of $\mathrm{h}$-BN/TP polymer composites. The BNNS/IL/polymer composites are extremely promising for various applications requiring highly TC and electrical insulation.
\end{abstract}

\section{Introduction}

Boron nitride nanosheet (BNNS), a 2D nanomaterial consisting of $\mathrm{B}$ atoms and $\mathrm{N}$ atoms, is a structural analogue of graphene..$^{\mathbf{1 - 4}}$ For use in various applications, BNNS has attracted increasing interest because it has extremely high thermal conductivity (TC, 300-2000 W m $\left.{ }^{-1} \mathrm{~K}^{-1}\right),{ }^{2-4}$ high electrical insulation, ${ }^{2,3}$ good mechanical properties, ${ }^{2,3,5}$ high heat resistance, ${ }^{\mathbf{1 , 3 , 6}}$ high chemical resistance, ${ }^{\mathbf{1 , 3 , 6}}$ and whiteness. Especially, the nanosheets' high TC and electrically insulating properties are extremely attractive for fabricating electrically insulating materials with high heat transfer properties. Producing insulating polymeric

Toyota Central R\&D Labs., Inc., Nagakute, Aichi 480-1192, Japan. E-mail: morishita-t@mosk.tytlabs.co.jp

$\dagger$ Electronic supplementary information (ESI) available: ESI tables and figures. See DOI: 10.1039/c7ra06691k materials that dissipate heat highly efficiently is crucially important for miniaturization, high performance, and high reliability of various applications including next generation power electronic devices, electric machinery, and communication equipment. ${ }^{7,8}$ Anisotropic nanocarbons such as carbon nanotubes and graphenes also exhibit high $\mathrm{TC} ;{ }^{9}$ therefore, the addition and dispersion of nanocarbons into polymer matrices increased the TCs of the polymers. ${ }^{7-11}$ However, nanocarbons have high electrical conductivity. For that reason, the addition of even small quantities of nanocarbons into polymer matrices increases electrical conductivity, ${ }^{\mathbf{1 1}, \mathbf{1 2}}$ and hence, they are unavailable for highly electrically insulating materials requiring high TC $\left(>3 \mathrm{~W} \mathrm{~m} \mathrm{~m}^{-1} \mathrm{~K}^{-1}\right)$. Therefore, for the applications described above, BNNS is an extremely attractive candidate. Nevertheless, producing large quantities of BNNSs is crucially important for these applications. Currently, chemical vapor deposition (CVD) methods ${ }^{\mathbf{1 3 , 1 4}}$ and liquid-phase exfoliation of 
bulk hexagonal boron nitrides (h-BNs) in selected solvents ${ }^{\mathbf{2 , 3}, 15-20}$ are popular for preparing BNNSs. CVD processing is effective for synthesizing large-area BNNSs on a metal substrate, ${ }^{\mathbf{1 3 , 1 4}}$ but this method requires the transfer of BNNSs from the substrate to an appropriate substrate or solvent. Actually, liquid-phase exfoliation of bulk h-BNs is attractive because it is extremely versatile and applicable to widely various environments, ${ }^{2,3,15-20}$ as in the case of exfoliation of graphites into graphenes. ${ }^{21-24}$ However, these wet approaches for exfoliating h-BNs usually involve strong and/or extended sonication ${ }^{15-17,20}$ leading to greatly decreased lateral sizes, or the use of toxic, strong acids. ${ }^{18,19}$ Therefore, as a milder liquid-phase exfoliation method, we recently reported that h-BNs were exfoliated into BNNSs in ionic liquids (ILs) under weak sonication. ${ }^{25}$ ILs are environmentally friendly alternatives to volatile organic solvents and strong acids, and ILs show physical adsorption on BNNS surfaces. This physical adsorption is expected to improve affinity not only with solvents but also with polymer matrices to give BNNS/polymer composites with high TC and electrical insulation.

As a polymer matrix for a filler/polymer composite, thermoplastic (TP) polymer recently has attracted growing interest compared with thermoset (TS) polymer ${ }^{26}$ because of its good molding processability, the ability to reform a part after consolidation, high recycling potential of the composites, and high impact resistance. Actually, TS polymers have been widely used for filler/polymer composites with high TCs; many studies have described improvement of TCs of BNNS/TS polymer composites $^{27-33}$ in comparison to BNNS/TP polymer composites $^{19,27,34-37}$ because increasing the TCs of BNNS/TS polymer composites is generally much easier than increasing those of BNNS/TP polymer composites (Table $\mathrm{S} 1 \dagger$ ). ${ }^{27}$ In general, wettability of BNNSs with TP polymers is lower than that with TS polymers. The uncured TS polymer monomers can give easier wetting on BNNS surfaces than TP polymers. Low wettability between BNNSs and a TP polymer matrix engenders higher thermal resistance at the interface by increased phonon scattering, and lower dispersibility of BNNSs in a TP polymer matrix. Moreover, although increasing the through-plane TC is more important than doing so for in-plane TC for the thermal management of most applications, the through-plane TCs of previously reported BNNS/TP polymer composites were generally much lower than the in-plane TCs (Table $\mathrm{S} 1 \dagger$ ) because of high interfacial thermal resistance and BNNS orientation along the plane in polymer matrices. For improving both throughplane and in-plane TC of BNNS/TP polymer composites, dispersing BNNS randomly in the matrices and increasing affinity between BNNS surfaces and TP polymer matrices are necessary. Covalent functionalization of BNNS surfaces or edges $^{38,39}$ increased solubility in solvents and matrices, but it engenders formation of defects on the surfaces and reduction of the lateral sizes, which degrades the physical properties. In the case of nanocarbon/polymer composites, ${ }^{\mathbf{4 0 - 4 2}}$ noncovalent functionalization of nanocarbons was effective for increasing dispersibility in the polymer matrices without damaging the nanocarbon surface structure. Similarly, noncovalent functionalization of BNNSs is expected to be effective to improve their dispersibility without damaging the BNNS surface.
Actually, noncovalent functionalization of BNNS with superacid improved the dispersibility in polymer matrices. ${ }^{19}$ However, the superacid is moisture-sensitive and the acidity is stronger than pure sulfuric acid. Therefore, during BNNS production using superacids, the use of large quantities of water is necessary to remove free superacid from the BNNS, thereby producing huge amounts of acidic wastewater.

For this study, as a much milder, much simpler and more environmentally friendly method, BNNS was exfoliated and noncovalently functionalized with ILs by one-step liquid-phase exfoliation. The obtained noncovalently functionalized BNNSs (BNNS/IL complexes) were used to fabricate BNNS/TP polymer composites, giving significant enhancement of both throughplane and in-plane TCs. Moreover, the optimum functionalization ratio and appropriate combinations of IL and polymer matrix species were found for additional enhancement of TC values.

\section{Experimental}

\subsection{Materials}

h-BNs (UHP-1K, 99.9 wt\% BN purity, $2.27 \mathrm{~g} \mathrm{~cm}^{-3}$ density, $\sim 24$ $\mu \mathrm{m}$ mean secondary particle size, $\sim 4.0 \mu \mathrm{m}$ mean lateral size of platelet; Showa Denko K.K., Japan) were used and dried under vacuum at $80{ }^{\circ} \mathrm{C}$ for $12 \mathrm{~h}$ before use. The mean secondary particle size and mean lateral size of platelet of the h-BN were estimated as average values using scanning electron microscopy (SEM) $(N=20)$. 1-Butyl-3-methylimidazolium bis (trifluoromethylsulfonyl)imide ([bmim] $\left.\mathrm{Tf}_{2} \mathrm{~N}\right]$ ) ( $\geq 98 \%$ purity, $1.44 \mathrm{~g} \mathrm{~cm}^{-3}$ density) was purchased from Sigma-Aldrich Corp. (USA). Also, 1-butyl-3-methylimidazolium hexafluorophosphate ([bmim] $\left[\mathrm{PF}_{6}\right]$ ) ( $\geq 99 \%$ purity, $1.38 \mathrm{~g} \mathrm{~cm}^{-3}$ density) was obtained from Kanto Chemical Co. Inc. (Japan). Poly(methyl methacrylate) (PMMA, grade $\mathrm{G}, 1.19 \mathrm{~g} \mathrm{~cm}^{-3}$ density) was purchased from Kuraray Co. Ltd., Japan. Polycarbonate (PC, E-2000, $1.20 \mathrm{~g} \mathrm{~cm}^{-3}$ density) was purchased from Mitsubishi Engineering-Plastics Corp., Japan. Polybutylene terephthalate (PBT, Duranex-2002, $1.31 \mathrm{~g} \mathrm{~cm}^{-3}$ density) was obtained from WinTech Polymer Ltd., Japan.

\subsection{Characterization}

High-resolution transmission electron microscopy (HRTEM) images were obtained with instruments (Titan 80-300; FEI or JEM-2100F; JEOL) operating at $200 \mathrm{kV}$. HRTEM samples were prepared by dispersing the BNNS/IL complexes in IPA under brief bath-sonication and dropping of the resulting dispersions onto microgrids. SEM images for morphologies of BNNS/IL/ PMMA composites were observed using an instrument (SU3500; Hitachi High-Technologies Corp.). For SEM measurements, frozen fracture surfaces of the films (approx. $0.3 \mathrm{~mm}$ thickness) of BNNS/IL/PMMA composites were prepared. The frozen fracture surfaces of the films were coated with Pt under pure argon by sputtering (E-1045 ion sputter; Hitachi HighTechnologies Corp.). X-ray photoelectron spectroscopy (XPS) data were collected using a spectrometer (Quantera SXM; Ulvac Phi Inc.) with a monochromated $\mathrm{Al}-\mathrm{K} \alpha(1486.6 \mathrm{eV})$. 
Experimental energy shifts due to charge up were corrected relative to the $\mathrm{C} 1 \mathrm{~s}$ peak at $284.6 \mathrm{eV}$ (C-C bond). X-ray powder diffraction (XRD) patterns were recorded at a scan rate of $50^{\circ}$ $\min ^{-1}$ with the Cu-K $\alpha(1.542 \AA)$ line using a multipurpose XRD system (Ultima IV; Rigaku Corp.). Powder samples were loaded onto XRD glass plates. Thermogravimetric analysis (TGA) measurements were performed (plus TG8120; Rigaku-Thermo). Samples were held at $100{ }^{\circ} \mathrm{C}$ for 30 min under $\mathrm{N}_{2}$ flow of $500 \mathrm{~mL}$ $\min ^{-1}$ and were heated to $600{ }^{\circ} \mathrm{C}$ at $10{ }^{\circ} \mathrm{C} \min ^{-1}$. The TC $(\kappa)(\mathrm{W}$ $\left.\mathrm{K}^{-1} \mathrm{~m}^{-1}\right)$ was calculated from the thermal diffusivity $(\alpha)\left(\mathrm{m}^{2}\right.$ $\left.\mathrm{s}^{-1}\right)$ as $\kappa=\alpha \rho c$, where $\rho$ stands for the density $\left(\mathrm{kg} \mathrm{m}^{-3}\right)$ and $c$ signifies the specific heat capacity $\left(\mathrm{J} \mathrm{K}^{-1} \mathrm{~kg}^{-1}\right)$ of composites. The density was measured using a water displacement method. The specific heat capacity was ascertained from differential scanning calorimetry (DSC) measurements taken using a calorimeter (DSC 7020; Seiko Instruments Inc.). The through-plane thermal diffusivity of each composite film $(10 \mathrm{~mm} \times 10 \mathrm{~mm}$; approx. $0.3 \mathrm{~mm}$ thickness) was measured at room temperature using a laser flash technique with a laser flash apparatus (LFA447 Nanoflash; Netzsch Inc.). The in-plane thermal diffusivity of the in-plane direction for each composite film $(10 \mathrm{~mm}$ $\times 10 \mathrm{~mm}$; approx. $0.3 \mathrm{~mm}$ thickness) was measured at room temperature with a thermo-wave analyzer (TA3; Bethel Co. Ltd.) under periodic laser heating. The average of three measurements was regarded as the thermal diffusivity. The volume resistivity of each composite film $(50 \mathrm{~mm} \times 50 \mathrm{~mm}$; approx. 0.3 $\mathrm{mm}$ thickness) was measured using a high-resistance meter (Agilent 4339B; Agilent Technologies Inc.) equipped with a resistivity cell (16008B; Agilent) with main electrode size of 26 $\mathrm{mm}$. The operating load was $5 \mathrm{kgf} ; 1000 \mathrm{~V}$ potential was applied to the film. The volume resistivity was measured after $1000 \mathrm{~V}$ potential application to the film for $20 \mathrm{~s}$. The average of four measurements was regarded as volume resistivity.

\subsection{Typical procedure for the preparation of BNNS/IL complexes}

After $75 \mathrm{~mL}$ of IL was added to a round-bottomed flask containing dried h-BN (375 mg), the mixture was subjected to bathsonication using an ultrasonic cleaner (B-220, $125 \mathrm{~W}$; Branson Ultrasonics Corp.) for $8 \mathrm{~h}$. The resulting dispersion was centrifuged at $3000 \mathrm{rpm}$ for $20 \mathrm{~min}$, giving BNNS/IL supernatant. The supernatant was subjected to vacuum filtration through a preweighted $0.1 \mu \mathrm{m}$ membrane filter and was then washed with acetone. BNNS/IL complex was obtained after drying under vacuum at $80{ }^{\circ} \mathrm{C}$ for $12 \mathrm{~h}$. The $\mathrm{BNNS} / \mathrm{IL}$ complexes were measured using TGA. The amount of BNNS in the BNNS/IL complex was estimated using the resulting weight loss corresponding to IL. The yields were calculated using $y=100 \times$ $M_{\mathrm{BNNS}} / M_{\mathrm{h}-\mathrm{BN}}$, where $M_{\mathrm{BNNS}}$ is the weight of BNNS and $M_{\mathrm{h}-\mathrm{BN}}$ is the weight of the h-BN.

\subsection{Preparation of $\mathrm{BNNS} /[\mathrm{bmim}]\left[\mathrm{PF}_{6}\right] / \mathrm{PMMA}$ composite films (BNNS content, $2 \mathrm{wt} \%$ )}

First, $62.8 \mathrm{mg}$ of $\mathrm{BNNS} /[\mathrm{bmim}]\left[\mathrm{PF}_{6}\right]$ complex, consisting of $60.0 \mathrm{mg}$ of BNNS and $2.8 \mathrm{mg}$ of $[\mathrm{bmim}]\left[\mathrm{PF}_{6}\right]$, was mixed with $2.0 \mathrm{~g}$ of acetone and bath-sonicated for $20 \mathrm{~min}$. The obtained
$\mathrm{BNNS} /[\mathrm{bmim}]\left[\mathrm{PF}_{6}\right] /$ acetone solution was mixed with a PMMA/ acetone $(3.0 \mathrm{~g} / 8.0 \mathrm{~g})$ solution under bath-sonication for $30 \mathrm{~min}$. The resulting $\mathrm{BNNS} /[\mathrm{bmim}]\left[\mathrm{PF}_{6}\right] / \mathrm{PMMA} /$ acetone solution was spread on a glass plate. Then acetone was naturally volatilized for at least $24 \mathrm{~h}$. BNNS/[bmim] $\left[\mathrm{PF}_{6}\right] / \mathrm{PMMA}$ (BNNS content, 2 wt $\% \approx 1.1$ vol\%) composite films with approx. 0.3 $\mathrm{mm}$ thickness were obtained after further drying at $50{ }^{\circ} \mathrm{C}$ for $12 \mathrm{~h}$ under vacuum to remove the residual acetone.

\subsection{Preparation of $\mathrm{BNNS} /[\mathrm{bmim}]\left[\mathrm{PF}_{6}\right] / \mathbf{P M M A}$ composite films (BNNS content, $50 \mathrm{wt} \%$ )}

After $157.1 \mathrm{mg}$ of $\mathrm{BNNS} /[\mathrm{bmim}]\left[\mathrm{PF}_{6}\right]$ complex, consisting of $150 \mathrm{mg}$ of BNNS and $7.1 \mathrm{mg}$ of $[\mathrm{bmim}]\left[\mathrm{PF}_{6}\right]$ was added to $1.0 \mathrm{~g}$ of acetone, the mixture was bath-sonicated for $20 \mathrm{~min}$, and subsequently mixed with PMMA/acetone (142.9 mg/1.0 g) solution under bath-sonication for $30 \mathrm{~min}$. The resulting BNNS/ [bmim $]\left[\mathrm{PF}_{6}\right] / \mathrm{PMMA} /$ acetone solution was spread on a glass plate. The acetone was naturally volatilized for at least $24 \mathrm{~h}$. After further drying at $50{ }^{\circ} \mathrm{C}$ for $12 \mathrm{~h}$ under vacuum to remove the residual acetone, $\mathrm{BNNS} /[\mathrm{bmim}]\left[\mathrm{PF}_{6}\right] / \mathrm{PMMA}$ (BNNS content, $50 \mathrm{wt} \% \approx 34 \mathrm{vol} \%$ ) composite films with approx. $0.3 \mathrm{~mm}$ thickness were obtained.

\subsection{Preparation of $\mathrm{BNNS} /[\mathrm{bmim}]\left[\mathrm{PF}_{6}\right] / \mathrm{PBT}$ composite films (BNNS content, $50 \mathrm{wt} \%$ )}

After $157.1 \mathrm{mg}$ of $\mathrm{BNNS} /[\mathrm{bmim}]\left[\mathrm{PF}_{6}\right]$ complex, consisting of $150 \mathrm{mg}$ of BNNS and $7.1 \mathrm{mg}$ of $[\mathrm{bmim}]\left[\mathrm{PF}_{6}\right]$, was added to $1.0 \mathrm{~g}$ of 1,1,1,3,3,3-hexafluoro-2-propanol (HFIP), the mixture was bath-sonicated for $20 \mathrm{~min}$, and subsequently mixed with PBT/ HFIP (142.9 $\mathrm{mg} / 2.0 \mathrm{~g})$ solution under bath-sonication for $30 \mathrm{~min}$. The obtained $\mathrm{BNNS} /[\mathrm{bmim}]\left[\mathrm{PF}_{6}\right] / \mathrm{PBT} / \mathrm{HFIP}$ solution was spread on a glass plate. Then HFIP was naturally volatilized for at least $24 \mathrm{~h}$. BNNS/[bmim] $\left[\mathrm{PF}_{6}\right] / \mathrm{PBT}$ (BNNS content, $50 \mathrm{wt} \%$ $\approx 37 \mathrm{vol} \%$ ) composite films with approx. $0.3 \mathrm{~mm}$ thickness were obtained after further drying at $50{ }^{\circ} \mathrm{C}$ for $12 \mathrm{~h}$ under vacuum to remove the residual HFIP.

\section{Results and discussion}

\subsection{Preparation and evaluation of BNNS/IL complexes}

Fig. 1a presents a schematic of preparation of BNNS/IL complexes by exfoliation and noncovalent functionalization of h-BN with ILs. The $[\mathrm{bmim}]\left[\mathrm{Tf}_{2} \mathrm{~N}\right]$ and $[\mathrm{bmim}]\left[\mathrm{PF}_{6}\right]$ (Fig. 1b) were used as ILs for exfoliation of h-BNs. For this study, large amounts of h-BNs $(375 \mathrm{mg})$ and ILs $(75 \mathrm{~mL})$ were used for exfoliation and noncovalent functionalization to obtain sufficient quantities ( $>\sim 75 \mathrm{mg}$ ) of BNNS/IL complexes for fabrication and evaluation of BNNS/IL/polymer composite films. First, h-BNs were exfoliated in ILs under bath-sonication, giving initial dispersions. Then, after centrifugation $(3000 \mathrm{rpm}, 20$ min) of the initial dispersions, BNNS/[bmim $]\left[\mathrm{Tf}_{2} \mathrm{~N}\right]$ dispersion and $\mathrm{BNNS} /[\mathrm{bmim}]\left[\mathrm{PF}_{6}\right]$ dispersion (Fig. 1c) were obtained by collecting the supernatants. BNNS/[bmim] $\left[\mathrm{Tf}_{2} \mathrm{~N}\right]$ complex and $\mathrm{BNNS} /[\mathrm{bmim}]\left[\mathrm{PF}_{6}\right]$ complex (Fig. 1d) were obtained after filtration, washing, and drying of the BNNS/IL dispersions. 
(a)

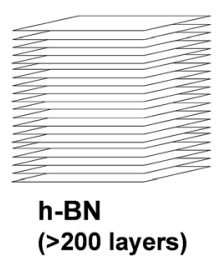

(b)

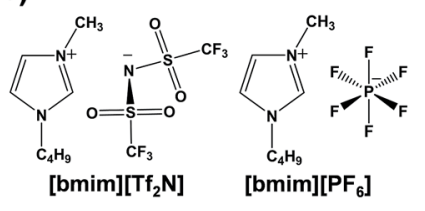

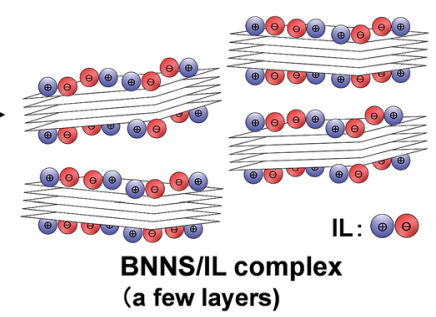

(c)

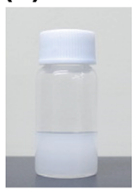

(d)

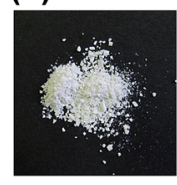

Fig. 1 (a) Schematic of preparation of BNNS/IL complexes by exfoliation and noncovalent functionalization of $h$-BNs with ILs. (b) Chemical structures of [bmim] $\left[\mathrm{Tf}_{2} \mathrm{~N}\right]$ and $[\mathrm{bmim}]\left[\mathrm{PF}_{6}\right]$. (c) Photograph of BNNS/[bmim] $\left[\mathrm{PF}_{6}\right]$ dispersion (supernatant) collected after centrifugation. (d) Photograph of BNNS/[bmim] $\left[\mathrm{PF}_{6}\right]$ complex powder.

Fig. 2a and b respectively depict HRTEM images of the obtained $\mathrm{BNNS} /[\mathrm{bmim}]\left[\mathrm{Tf}_{2} \mathrm{~N}\right]$ complex and $\mathrm{BNNS} /[\mathrm{bmim}]\left[\mathrm{PF}_{6}\right]$ complex. The layers of the BNNSs were counted by their distinguishable curled edges, which were visible in HRTEM images. $^{2}$ The HRTEM images of BNNS edges of BNNS/[bmim] $\left[\mathrm{Tf}_{2} \mathrm{~N}\right]$ complexes and $\mathrm{BNNS} /[\mathrm{bmim}]\left[\mathrm{PF}_{6}\right]$ complexes clearly showed their few-layers-thick nature (Fig. 2a, b and $\mathrm{S} 1 \dagger$ ). Thickness distributions of the BNNS/IL complexes (Fig. 3a and b) revealed that $\mathrm{BNNS} /[\mathrm{bmim}]\left[\mathrm{Tf}_{2} \mathrm{~N}\right]$ complexes consisted mainly of fewer than 20 layers (Fig. 3a, the average number of layers: 12.1). The numbers of layers of $\mathrm{BNNS} /[\mathrm{bmim}]\left[\mathrm{PF}_{6}\right]$ complexes were predominantly fewer than 25 layers (Fig. 3b; 15.9 average number of layers). Moreover, the BNNS/[bmim] $\left[\mathrm{Tf}_{2} \mathrm{~N}\right]$ complexes were thinner than the $\mathrm{BNNS} /[\mathrm{bmim}]\left[\mathrm{PF}_{6}\right]$ complexes. The BNNS lattice of $\mathrm{BNNS} /[\mathrm{bmim}]\left[\mathrm{PF}_{6}\right]$ complex (Fig. 3d; approx. $2.9 \mu \mathrm{m}$ average lattice size) was larger than that of $\mathrm{BNNS} /[\mathrm{bmim}]\left[\mathrm{Tf}_{2} \mathrm{~N}\right]$ complexes (Fig. 3c; approx. $2.3 \mu \mathrm{m}$ average lattice size). [bmim] $\left[\mathrm{PF}_{6}\right]$ is a better solvent for solubilizing BNNSs than [bmim] $\left[\mathrm{Tf}_{2} \mathrm{~N}\right]$ as described later. Therefore, even after centrifugation at the same condition, $[\mathrm{bmim}]\left[\mathrm{PF}_{6}\right]$ solubilized thicker and larger BNNSs than $[\mathrm{bmim}]\left[\mathrm{Tf}_{2} \mathrm{~N}\right]$. Better BNNS dispersion in $[\mathrm{bmim}]\left[\mathrm{PF}_{6}\right]$ is regarded as resulting from higher affinity of $[\mathrm{bmim}]\left[\mathrm{PF}_{6}\right]$ with BNNS under sonication. In addition, the selected area electron diffraction (SAED) pattern (Fig. 2c) revealed that $\mathrm{BNNS} /[\mathrm{bmim}]\left[\mathrm{PF}_{6}\right]$ complex had highcrystallinity hexagonal BN structures. XRD patterns of the BNNS/[bmim $]\left[\mathrm{PF}_{6}\right]$ complexes (Fig. 2d) showed sharp BN (002) and (004) peaks at $2 \theta$ values of $\sim 26.6^{\circ}$ and $\sim 55.0^{\circ}$, respectively, demonstrating its high-crystallinity BN structure. The (002) and (004) peak intensities were weaker than those of pristine h-BNs, probably because of thinner BNNS layers than those of pristine h-BN. The XRD (002) and (004) peak intensities for BNNS/ $[\mathrm{bmim}]\left[\mathrm{Tf}_{2} \mathrm{~N}\right]$ complex (Fig. $\mathrm{S} 2 \dagger$ ) were even weaker than those for $\mathrm{BNNS} /[\mathrm{bmim}]\left[\mathrm{PF}_{6}\right]$ complex because of its thinner BNNS layer structure. In addition, the $\mathrm{BNNS} /[\mathrm{bmim}]\left[\mathrm{PF}_{6}\right]$ complex and $\mathrm{BNNS} /[\mathrm{bmim}]\left[\mathrm{Tf}_{2} \mathrm{~N}\right]$ complex showed much lower intensity (I)

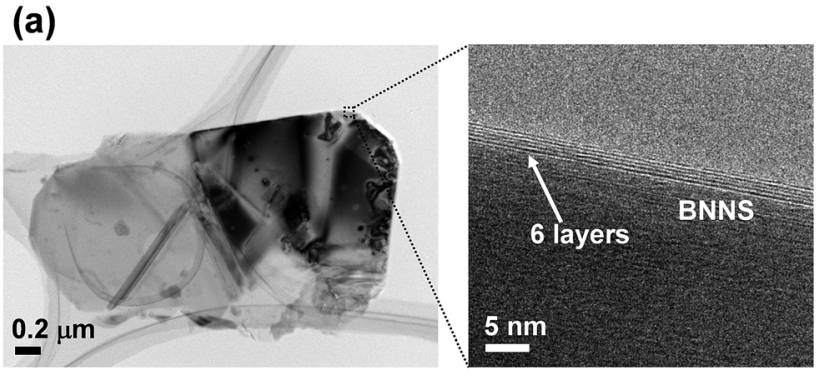

(b)

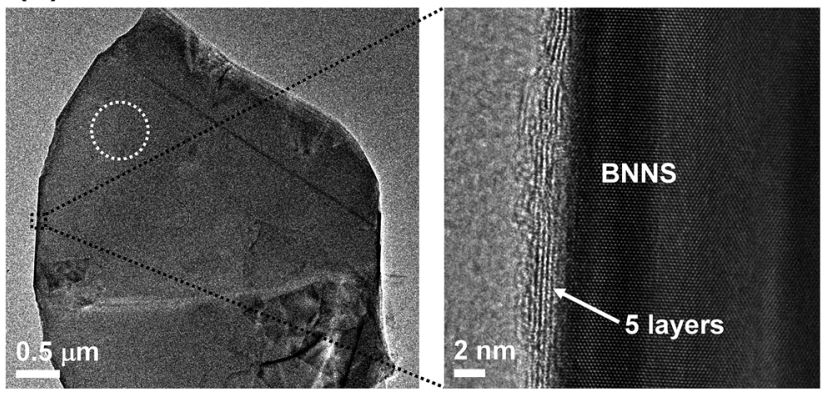

(c)

(d)
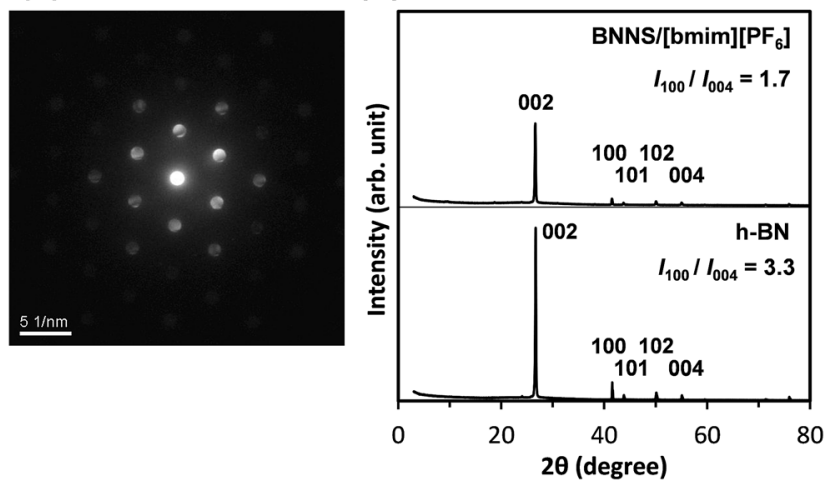

Fig. 2 (a) HRTEM images of BNNS/[bmim] $\left[\mathrm{Tf}_{2} \mathrm{~N}\right]$ complexes. (b) HRTEM images of BNNS/[bmim] $\left[\mathrm{PF}_{6}\right]$ complexes. (c) SAED pattern of the area marked by the white dotted circle in (b). (d) XRD spectra of BNNS/[bmim] $\left[\mathrm{PF}_{6}\right]$ complex and h-BN.

ratios between (100) and (004) planes $\left(I_{100} / I_{004}\right)$ than those of h$\mathrm{BN}$ (Fig. 2d and $\mathrm{S} 2 \dagger$ ), which is consistent with previously reported results. ${ }^{\mathbf{4 3 , 4 4}}$ Because BNNS/IL complexes were very thin, the (002) crystal faces of BNNS/IL complexes were more readily oriented along the plane of the XRD glass plate and were more selectively exposed on the plate than those of h-BN.

Table 1 presents properties of BNNS/IL complexes prepared using different sonication conditions. After sonication and centrifugation of $375 \mathrm{mg}$ of h-BNs in $75 \mathrm{~mL}$ of each IL, the concentrations (solubilities) of BNNSs in [bmim] $\left[\mathrm{Tf}_{2} \mathrm{~N}\right]$ and [bmim $]\left[\mathrm{PF}_{6}\right]$ were, respectively, approx. $0.30 \mathrm{mg} \mathrm{mL}^{-1}$ and approx. $1.09 \mathrm{mg} \mathrm{mL}^{-1}$ (Table 1, 1a and 2a). The [bmim] $\left[\mathrm{PF}_{6}\right]$ afforded much higher BNNS concentration than $[\mathrm{bmim}]\left[\mathrm{Tf}_{2} \mathrm{~N}\right]$, which demonstrates that anion species played an important role in improving the BNNS concentrations. The BNNS concentrations also depended on the volume of ILs used for sonication experiments. The concentrations of BNNSs in $[$ bmim $]\left[\mathrm{Tf}_{2} \mathrm{~N}\right]$ and $[\mathrm{bmim}]\left[\mathrm{PF}_{6}\right]($ Table 1, 1a and 2a) were lower 
(a)

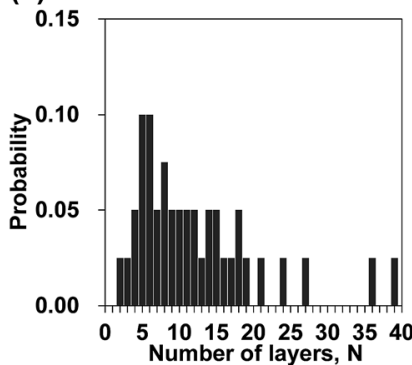

(b)

(c)

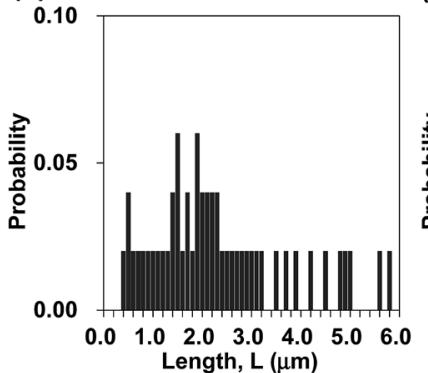

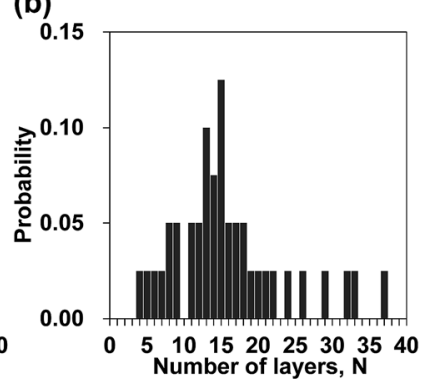

(d)

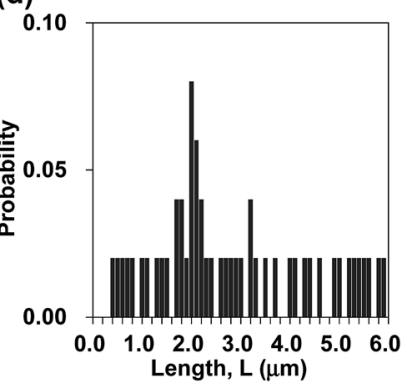

Fig. 3 Thickness distribution of (a) BNNS/[bmim] $\left[\mathrm{Tf}_{2} \mathrm{~N}\right]$ complex and (b) $\mathrm{BNNS} /[\mathrm{bmim}]\left[\mathrm{PF}_{6}\right]$ complex. Length distribution of (c) BNNS/ [bmim] $\left[\mathrm{Tf}_{2} \mathrm{~N}\right]$ complex and (d) BNNS/[bmim] $\left[\mathrm{PF}_{6}\right]$ complex. Here, 40 flakes were measured using HRTEM for the thickness histogram; 50 flakes were measured using HRTEM for the length histogram.

than those in the case of smaller scale using $150 \mathrm{mg}$ of h-BNs in $30 \mathrm{~mL}$ of ILs (Table $\mathbf{1}, \mathbf{1} \mathbf{b}$ and $\mathbf{2 b}$ ). However, prolonged sonication (from $8 \mathrm{~h}$ to $16 \mathrm{~h}$ ) increased the BNNS concentration in each $\mathrm{IL}$ (Table 1, 1c and $2 \mathbf{c}$ ). The sonic energy input to the sample is known to be sensitive to various conditions such as the volume of dispersion, the water level, the exact position in the bath, and vessel shape. ${ }^{22}$ For this study, each exfoliation experiment had the same initial h-BN concentration ( $5 \mathrm{mg} \mathrm{mL}^{-1}$ ), almost equal water level, and exact position in the bath. Therefore, increasing the volume of BNNS/IL dispersion (the dispersion height) decreased the sonic energy input to the h-BN in IL solution, leading to large decreases of the BNNS concentrations.

The functionalization ratio (FR) of BNNS/IL complexes, defined as IL/BNNS mass ratio estimated by TGA weight loss

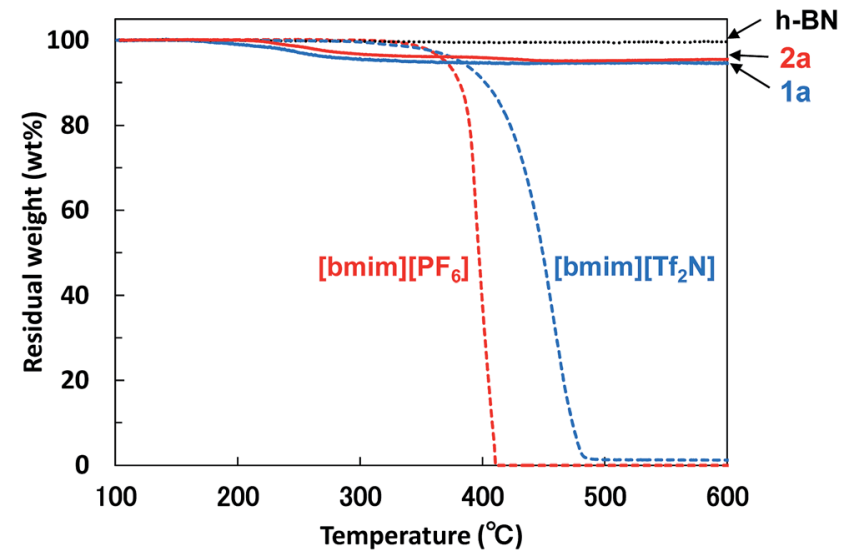

Fig. 4 TGA diagrams of BNNS/[bmim] $\left[\mathrm{Tf}_{2} \mathrm{~N}\right]$ complex 1a, BNNS/ [bmim] $\left[\mathrm{PF}_{6}\right]$ complex $2 \mathrm{a}, \mathrm{h}-\mathrm{BN}$, [bmim] $\left[\mathrm{Tf}_{2} \mathrm{~N}\right]$, and $[\mathrm{bmim}]\left[\mathrm{PF}_{6}\right]$. Heating rate $=10^{\circ} \mathrm{C} \min ^{-1}, \mathrm{~N}_{2}$ atmosphere.

(Fig. 4), was also evaluated (Table 1). [bmim] [ $\left.\mathrm{Tf}_{2} \mathrm{~N}\right]$ and [bmim] $\left[\mathrm{PF}_{6}\right]$ almost perfectly decomposed until approx. $500{ }^{\circ} \mathrm{C}$; h-BN showed no weight loss (Fig. 4). Therefore, the TGA weight losses can be attributed to ILs physically adsorbed on the BNNS surfaces. When using $75 \mathrm{~mL}$ of ILs after $8 \mathrm{~h}$ sonication, the FRs of BNNS/IL complexes (Table 1, 1a and 2a) were much smaller than those of BNNS/IL complexes prepared using $30 \mathrm{~mL}$ of ILs (1b and $\mathbf{2 b}$ ). However, prolonged sonication increased the FRs (1c and 2c). The FR of BNNS/[bmim $]\left[\mathrm{PF}_{6}\right]$ complexes after $6 \mathrm{~h}$ sonication was extremely small $(0.006,2 d)$. The FR increased greatly from $6 \mathrm{~h}$ to $8 \mathrm{~h}$. After $8 \mathrm{~h}$ sonication of h-BNs in $30 \mathrm{~mL}$ of [bmim $]\left[\mathrm{PF}_{6}\right]$ (Table 1, 2b), the $\mathrm{BNNS} /[\mathrm{bmim}]\left[\mathrm{PF}_{6}\right]$ dispersion had a very small amount of vapor with some odor, although the $\mathrm{BNNS} /[\mathrm{bmim}]\left[\mathrm{PF}_{6}\right]$ dispersion after $6 \mathrm{~h}$ sonication had no odor. One report of the literature ${ }^{45}$ has described that [bmim] cation of $[\mathrm{bmim}]\left[\mathrm{PF}_{6}\right]$ decomposed under strong sonication (at $85^{\circ} \mathrm{C}$ ). Sonication creates cavitation, which involves the formation, growth, and implosive collapse of bubbles in a liquid, leading to creation of hot spots with momentarily high temperatures as high as $5000 \mathrm{~K}$ (and cooling rates in excess of $10^{10} \mathrm{~K} \mathrm{~s}^{-1}$ ). ${ }^{45,46}$ The literature ${ }^{45}$ has also described that the decomposition of [bmim] cations of $[\mathrm{bmim}]\left[\mathrm{PF}_{6}\right]$ produced gases containing nitriles

Table 1 Properties of BNNS/IL complexes obtained by different conditions

\begin{tabular}{|c|c|c|c|c|c|c|c|}
\hline Code & $\mathrm{IL}$ & $\operatorname{Vol}^{a}(\mathrm{~mL})$ & $\operatorname{Time}^{b}(\mathrm{~h})$ & Conc. $^{c}\left(\mathrm{mg} \mathrm{mL}{ }^{-1}\right)$ & The number of layers ${ }^{d}$ & $\mathrm{FR}^{e}$ & Yield $^{f}(\%)$ \\
\hline 1a & {$[\mathrm{bmim}]\left[\mathrm{Tf}_{2} \mathrm{~N}\right]$} & 75 & 8 & 0.30 & 12.1 & 0.056 & 5.7 \\
\hline $1 \mathbf{b}$ & {$[\mathrm{bmim}]\left[\mathrm{Tf}_{2} \mathrm{~N}\right]$} & 30 & 8 & 0.46 & 6.0 & 0.100 & 9.0 \\
\hline $2 a$ & {$[\mathrm{bmim}]\left[\mathrm{PF}_{6}\right]$} & 75 & 8 & 1.09 & 15.9 & 0.047 & 20.7 \\
\hline $2 \mathbf{b}$ & {$[\mathrm{bmim}]\left[\mathrm{PF}_{6}\right]$} & 30 & 8 & 1.62 & 8.1 & 0.215 & 31.0 \\
\hline $2 c$ & {$[\mathrm{bmim}]\left[\mathrm{PF}_{6}\right]$} & 75 & 16 & 1.50 & 10.4 & 0.121 & 27.1 \\
\hline
\end{tabular}

${ }^{a}$ Volume of IL (initial concentration of the starting material h-BN in IL: $5 \mathrm{mg} \mathrm{mL} \mathbf{m}^{-1}$ ). ${ }^{b}$ Time of bath-sonication. ${ }^{c}$ Average BNNS concentration in the supernatant calculated using the weight of BNNS estimated from the weight of the obtained BNNS/IL complex and the TGA weight loss corresponding to IL. ${ }^{d}$ Average value of the number of layers measured by HRTEM $(N=40) .{ }^{e}$ IL/BNNS mass ratio of BNNS/IL complex.

${ }^{f}$ Average yield of BNNS. 
(acetonitrile/isocyanomethane and 2-propenenitrile) and light hydrocarbons (2-methylpropane, pent-3-en-1-yne, 1,3-butadiyne and 1,3-butadiene). Actually, the odor from the BNNS/[bmim] $\left[\mathrm{PF}_{6}\right]$ dispersion after $8 \mathrm{~h}$ sonication was similar to that of acetonitrile. Meanwhile, reportedly, fluoride-containing species attributable to possible hydrolysis of $\left[\mathrm{PF}_{6}\right]$ anions were not detected in the decomposition gases under sonication. ${ }^{45}$ Therefore, it is suggested that some [bmim] cations of [bmim] $\left[\mathrm{PF}_{6}\right]$ decomposed under $8 \mathrm{~h}$ sonication, and the [bmim] cation decomposition might be related with the significant increase of the FRs. Meanwhile, the BNNS/[bmim] [Tf $\left.{ }_{2} \mathrm{~N}\right]$ complexes showed the FR value of 0.042 after $6 \mathrm{~h}$ sonication. The difference in the FR values between $6 \mathrm{~h}$ and $8 \mathrm{~h}$ sonication treatments was not large. $[\mathrm{bmim}]\left[\mathrm{Tf}_{2} \mathrm{~N}\right]$ is considered to be less stable than [bmim] $\left[\mathrm{PF}_{6}\right]$ under sonication, because $[\mathrm{bmim}]\left[\mathrm{Tf}_{2} \mathrm{~N}\right]$ becomes very light yellow and has a small amount of vapor with some odor similar to acetonitrile even after $3 \mathrm{~h}$ bath-sonication, indicating the decomposition of some [bmim] cations of $[\mathrm{bmim}]\left[\mathrm{Tf}_{2} \mathrm{~N}\right]$ under sonication. The decomposition of some [bmim] cations of $[\mathrm{bmim}]\left[\mathrm{PF}_{6}\right]$ or $[\mathrm{bmim}]\left[\mathrm{Tf}_{2} \mathrm{~N}\right]$ might engender less screening of $\left[\mathrm{PF}_{6}\right]$ or $\left[\mathrm{Tf}_{2} \mathrm{~N}\right]$ anions, which is regarded as an increase of anion- $\pi$ interaction between $\left[\mathrm{PF}_{6}\right]$ or $\left[\mathrm{Tf}_{2} \mathrm{~N}\right]$ anions and BNNS surfaces. Anion- $\pi$ interaction between $\left[\mathrm{PF}_{6}\right]$ or $\left[\mathrm{Tf}_{2} \mathrm{~N}\right]$ anions and BNNS surfaces species are considered to play an important role in improving the FRs. Actually, the quantum theory of atoms in molecules for interactions between h-BN surfaces and $[\mathrm{bmim}]\left[\mathrm{PF}_{6}\right]$ or $[\mathrm{bmim}]\left[\mathrm{Tf}_{2} \mathrm{~N}\right]^{47}$ also suggests that $\left[\mathrm{PF}_{6}\right]$ or $\left[\mathrm{Tf}_{2} \mathrm{~N}\right]$ anions in the ILs have a stronger interaction (anion- $\pi$ interaction) with the h-BN surface than the [bmim] cations.

The XPS P 2p spectrum of 2a (Fig. 5a) showed a peak at approx. $134 \mathrm{eV}$, which is consistent with the peak for $\left[\mathrm{PF}_{6}\right]$ anion. ${ }^{48}$ The XPS F 1s spectrum of 2a (Fig. 5b) showed a peak at approx. $687 \mathrm{eV}$, which was attributed to $\left[\mathrm{PF}_{6}\right]$ anion. ${ }^{48-50}$ These XPS spectra indicate the attachment of $\left[\mathrm{PF}_{6}\right]$ anions on the BNNS surfaces. In addition, the XPS surface elemental analysis for 2a (Table S2 $\dagger$ ) shows that the F/P ratio was approx. 8.5, which roughly matches the ideal $\mathrm{F} / \mathrm{P}$ ratio (approx. 6) for $\left[\mathrm{PF}_{6}\right]$ anions. Comparison of XPS surface elemental analysis for 2a and h-BN (Table S2 $\dagger$ ) shows that the carbon content for 2 a increases compared with that for h-BN, which results from the (a)

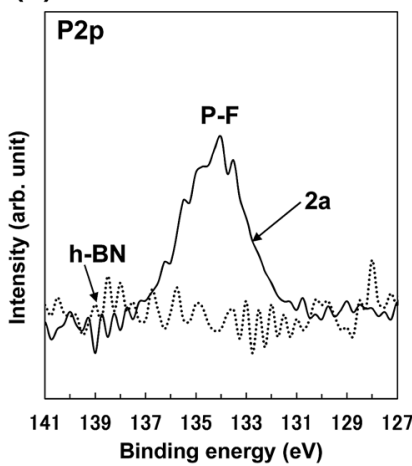

(b)

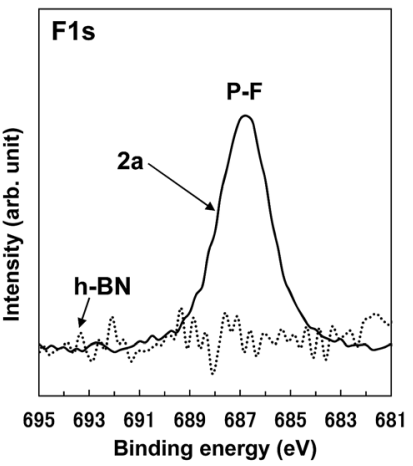

Fig. 5 (a) $P 2 p$ and (b) F 1s XPS spectra of BNNS/[bmim] $\left[\mathrm{PF}_{6}\right]$ complex $2 a$ and $h-B N$ attachment of [bmim] cations on BNNS surfaces. The XPS B 1s and $\mathrm{N}$ 1s spectra for $2 \mathrm{a}$ (Fig. S3†) showed fundamentally equal binding energies to those for h-BN, which is consistent with previously reported results for BNNSs. ${ }^{2}$ The XPS B $1 \mathrm{~s}$ and $\mathrm{N} 1 \mathrm{~s}$ spectra for 2a showed no clear peaks indicating covalent functionalization of $\mathrm{B}$ and $\mathrm{N}$ atoms. These results demonstrate that the BNNSs were noncovalently functionalized with $\left[\mathrm{bmim}^{2}\right]\left[\mathrm{PF}_{6}\right]$. On the other hand, as shown in Table 1, the yields of BNNS for $\mathrm{BNNS} /[\mathrm{bmim}]\left[\mathrm{PF}_{6}\right]$ complexes were higher than those for BNNS/ $[\mathrm{bmim}]\left[\mathrm{Tf}_{2} \mathrm{~N}\right]$ complexes. The yields for $\mathrm{BNNS} /[\mathrm{bmim}]\left[\mathrm{Tf}_{2} \mathrm{~N}\right]$ complex 1a and $\mathrm{BNNS} /[\mathrm{bmim}]\left[\mathrm{PF}_{6}\right]$ complex 2a were, respectively, $5.7 \pm 1.0 \%$ and $20.7 \pm 4.5 \%$ (Table 1 ).

\subsection{Fabrication and evaluation of thermal conductivities of BNNS/IL/polymer composites}

First, PMMA was used as a TP polymer because of its high solubility in common organic solvents with a low boiling point, such as acetone. BNNS/[bmim] $\left[\mathrm{PF}_{6}\right]$ complexes were used for preparing BNNS/IL/PMMA composites because of their higher yield than those of $\mathrm{BNNS} /[\mathrm{bmim}]\left[\mathrm{Tf}_{2} \mathrm{~N}\right]$ complexes (Table 1). $\mathrm{BNNS} /[\mathrm{bmim}]\left[\mathrm{PF}_{6}\right]$ complexes were dispersed in acetone under bath-sonication for $20 \mathrm{~min}$. The resulting dispersion was mixed with PMMA/acetone solutions. After bath-sonication for $30 \mathrm{~min}$, $\mathrm{BNNS} /[\mathrm{bmim}]\left[\mathrm{PF}_{6}\right] / \mathrm{PMMA} /$ acetone solutions were obtained (Fig. 6a). BNNS/[bmim] $\left[\mathrm{PF}_{6}\right]$ complexes were well dispersed in PMMA/acetone solutions. The PMMA/acetone solutions have high viscosity. Therefore the use of premade BNNS/[bmim] $\left[\mathrm{PF}_{6}\right] /$ acetone solutions was extremely effective for preparing $\mathrm{BNNS} /[\mathrm{bmim}]\left[\mathrm{PF}_{6}\right] / \mathrm{PMMA} /$ acetone solutions in which BNNS/ [bmim $]\left[\mathrm{PF}_{6}\right]$ complexes were uniformly dispersed. When BNNS/ [bmim $]\left[\mathrm{PF}_{6}\right]$ complexes were directly added to PMMA/acetone solutions, some BNNS coagulation was observed in the solution even after bath-sonication for $50 \mathrm{~min}$, which is caused mainly by high-viscosity PMMA/acetone solutions. The solutions were spread on glass plates. Then $\mathrm{BNNS} /[\mathrm{bmim}]\left[\mathrm{PF}_{6}\right] /$ PMMA composite films were prepared after drying. Additionally, h-BN/PMMA composite films were also prepared. The BNNS/[bmim] $]\left[\mathrm{PF}_{6}\right] / \mathrm{PMMA}$ composite films showed good surface appearance (Fig. 6b and c), although the h-BN/PMMA composite films showed uneven dispersion of h-BN particles (Fig. 6d).

Fig. 7 shows SEM images of frozen fracture surfaces of the films of BNNS/[bmim $]\left[\mathrm{PF}_{6}\right] / \mathrm{PMMA}$ composites and h-BN/PMMA (a)

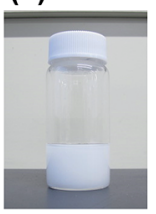

(b)

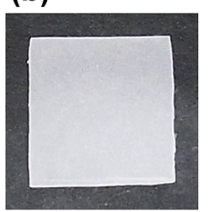

(c)

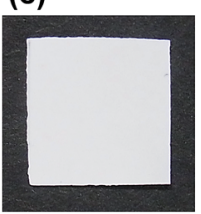

(d)

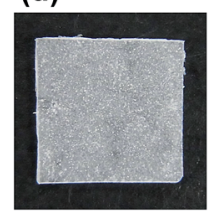

Fig. 6 Photographs of (a) BNNS/[bmim] $\left[\mathrm{PF}_{6}\right]$ (2a)/PMMA/acetone $(62.8 \mathrm{mg} / 3.0 \mathrm{~g} / 10 \mathrm{~g})$ solution, (b) film of 2a/PMMA composites containing $2 \mathrm{wt} \%$ of BNNS, (c) film of $2 \mathrm{a} / \mathrm{PMMA}$ composites containing $24.5 \mathrm{wt} \%$ of BNNS, and (d) film of $\mathrm{h}-\mathrm{BN} / \mathrm{PMMA}$ (2 wt\%/98 wt\%) composites. Each film has approx. $0.3 \mathrm{~mm}$ thickness. 
composite. Actually, the BNNSs were well dispersed in the PMMA matrix (Fig. 7a and c), although h-BN showed uneven dispersion in the matrix (Fig. 7b). This even dispersion results from physical adsorption of $\left[\mathrm{bmim}^{-}\left[\mathrm{PF}_{6}\right]\right.$ on the BNNS surfaces giving good affinity with PMMA matrix because PMMA is known to have good affinity with ILs having $\left[\mathrm{PF}_{6}\right]$ anions. ${ }^{51,52} \mathrm{~h}-\mathrm{BN} /$ PMMA composite films were much more brittle than BNNS/ [bmim $]\left[\mathrm{PF}_{6}\right] / \mathrm{PMMA}$ composite films. The $\mathrm{BNNS} /[\mathrm{bmim}]\left[\mathrm{PF}_{6}\right] /$ PMMA composite films have good flexibility (Fig. S4†), which is because of the good compatibility of BNNS/[bmim] $\left[\mathrm{PF}_{6}\right]$ with PMMA. The through-plane TC of h-BN/PMMA composite containing $2 \mathrm{wt} \%$ of h-BN was $0.247 \mathrm{~W} \mathrm{~m}^{-1} \mathrm{~K}^{-1}$ (Fig. 8a), which was only 1.1 times higher than that of pristine PMMA $\left(0.225 \mathrm{~W} \mathrm{~m}^{-1}\right.$ $\left.\mathrm{K}^{-1}\right)$. However, the through-plane TC of BNNS/[bmim $]\left[\mathrm{PF}_{6}\right](\mathbf{2 a}) /$ PMMA composite containing $2 \mathrm{wt} \%(\approx 1.1 \mathrm{vol} \%)$ of BNNS increased by $37 \%\left(0.309 \mathrm{~W} \mathrm{~m}^{-1} \mathrm{~K}^{-1}\right)$ compared with that of PMMA. The through-plane TC of 2a/PMMA composites containing $24.5 \mathrm{wt} \%$ ( $\approx 14.5 \mathrm{vol} \%$ ) of BNNS was $0.971 \mathrm{~W} \mathrm{~m}^{-1} \mathrm{~K}^{-1}$, which was much larger than that of h-BN/PMMA (24.5 wt\%/75.5 wt $\%)$ composites $\left(0.520 \mathrm{~W} \mathrm{~m}^{-1} \mathrm{~K}^{-1}\right)$. The in-plane TC of $2 \mathrm{a} /$ PMMA composites was also evaluated. The in-plane TC of 2a/ PMMA composites containing $2 \mathrm{wt} \%$ of BNNS was $0.360 \mathrm{~W} \mathrm{~m}^{-1}$ $\mathrm{K}^{-1}$, which was larger than the through-plane $\mathrm{TC}\left(0.309 \mathrm{~W} \mathrm{~m}^{-1}\right.$ $\left.\mathrm{K}^{-1}\right)$ and in-plane TC of pristine PMMA $\left(0.278 \mathrm{~W} \mathrm{~m}^{-1} \mathrm{~K}^{-1}\right)$ (Fig. 8a). In addition, the in-plane TC of 2a/PMMA composites containing $24.5 \mathrm{wt} \%$ of BNNS was $1.49 \mathrm{~W} \mathrm{~m}^{-1} \mathrm{~K}^{-1}$, which was 1.53 times of the through-plane TC $\left(0.971 \mathrm{~W} \mathrm{~m}^{-1} \mathrm{~K}^{-1}\right)$. However, the difference between through-plane and in-plane (a)

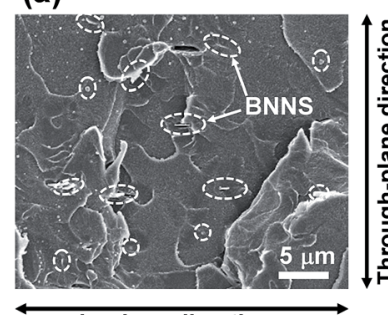

In-plane direction (b)

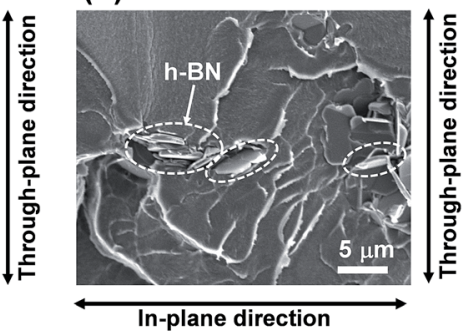

In-plane direction (c)

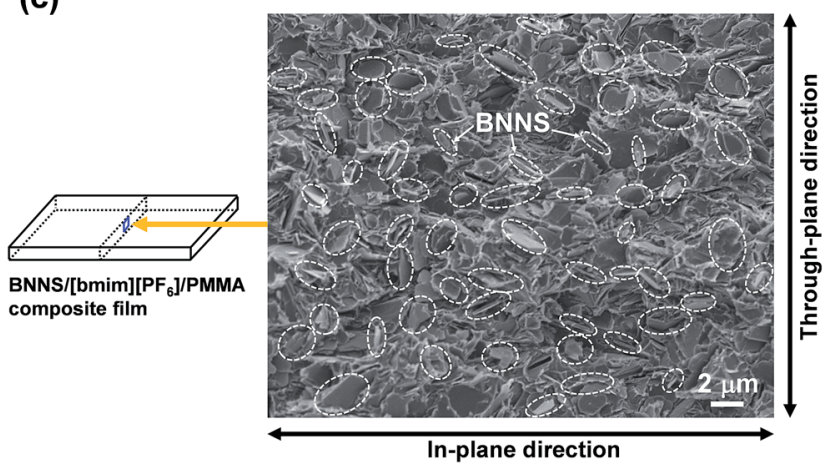

Fig. 7 SEM images of frozen fracture surfaces of the films of (a) BNNS/ [bmim] $\left[\mathrm{PF}_{6}\right] / \mathrm{PMMA}$ composite containing $2 \mathrm{wt} \%$ of BNNS, (b) h-BN/ PMMA composite containing $2 \mathrm{wt} \%$ of $\mathrm{h}-\mathrm{BN}$, and (c) BNNS/[bmim] $\left[\mathrm{PF}_{6}\right] / \mathrm{PMMA}$ composite containing $24.5 \mathrm{wt} \%$ of BNNS. Some BNNSs and $\mathrm{h}-\mathrm{BNs}$ are surrounded by white dotted-line circles in the figures. (a)

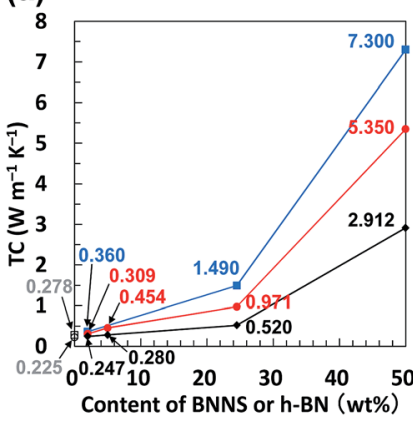

(b)

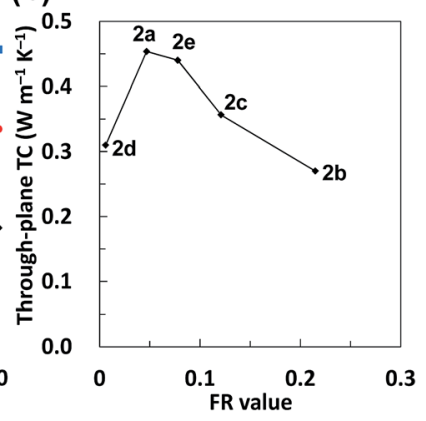

Fig. 8 (a) Through-plane TCs of 2a/PMMA composite films ( $)$ and in-plane TCs of 2a/PMMA composite films ( $\mathbf{\square})$, through-plane TCs of h-BN/PMMA composite films ( ) , through-plane TC of PMMA films (O), and in-plane TC of PMMA films ( $\square$ ). (b) Through-plane TCs of films of BNNS/[bmim] $\left[\mathrm{PF}_{6}\right] / P M M A$ composites using BNNS/[bmim] $\left[\mathrm{PF}_{6}\right]$ complexes $(2 \mathrm{a}-2 \mathrm{e})$ with different $\mathrm{FR}$ values (each composite film contains $5 \mathrm{wt} \%$ of BNNS).

TC was not large because BNNSs were randomly dispersed in the PMMA matrix (Fig. 7c). This random dispersion of BNNS results from noncovalent functionalization of BNNSs with $[\mathrm{bmim}]\left[\mathrm{PF}_{6}\right]$ and the use of predispersed $\mathrm{BNNS} /[\mathrm{bmim}]\left[\mathrm{PF}_{6}\right] /$ acetone solutions.

When BNNS/[bmim] $]\left[\mathrm{PF}_{6}\right]$ complex with higher FR (FR = 0.215 , Table $1,2 \mathbf{b}$ ) was used, the through-plane TC of the obtained BNNS/[bmim] $\left[\mathrm{PF}_{6}\right] / \mathrm{PMMA}$ composite containing 24.5 $\mathrm{wt} \%$ of BNNS was extremely low $\left(0.440 \mathrm{~W} \mathrm{~m}^{-1} \mathrm{~K}^{-1}\right)$ compared with the through-plane TC $\left(0.971 \mathrm{~W} \mathrm{~m}^{-1} \mathrm{~K}^{-1}\right)$ using 2a with an FR value of 0.047 . The marked increase of the amount of [bmim] $\left[\mathrm{PF}_{6}\right]$ on BNNS surfaces is regarded as engendering an increase of phonon scattering at the interface because the $[\mathrm{bmim}]\left[\mathrm{PF}_{6}\right]$ residue on BNNS surface is amorphous. Fig. 8b shows throughplane TCs of films of $\mathrm{BNNS} /[\mathrm{bmim}]\left[\mathrm{PF}_{6}\right] / \mathrm{PMMA}$ composites containing $5 \mathrm{wt} \%$ of BNNSs with different FR values. There is an optimum FR value observed at around 0.05 (Fig. 8b). Larger amounts of $[\mathrm{bmim}]\left[\mathrm{PF}_{6}\right]$ on the BNNS surface led to much lower TC because $[\mathrm{bmim}]\left[\mathrm{PF}_{6}\right]$ itself is amorphous, having very low TC. Meanwhile, lower amounts of $\left[\mathrm{bmim}^{\mathrm{b}}\right]\left[\mathrm{PF}_{6}\right]$ on the BNNS surfaces caused thicker BNNS layers and lower affinity between BNNS and PMMA, leading to lower TC (Fig. 8b, 2d). This result demonstrates that adjusting the FR value for BNNS/IL complex is an important factor for improving the TC of the composite. The through-plane and in-plane TCs of the BNNS/[bmim] $\left[\mathrm{PF}_{6}\right] /$ PMMA composites with optimum FR value $(\mathrm{FR}=0.047)$ were both improved significantly (approx. $5.35 \mathrm{~W} \mathrm{~m}^{-1} \mathrm{~K}^{-1}$, and approx. $7.30 \mathrm{~W} \mathrm{~m}^{-1} \mathrm{~K}^{-1}$, respectively) with $50 \mathrm{wt} \%(\approx 34 \mathrm{vol} \%)$ BNNS loading. The through-plane and in-plane TCs were much higher than those of h-BN/PMMA (50 wt $\% / 50 \mathrm{wt} \%$ ) composites (approx. $2.91 \mathrm{~W} \mathrm{~m}^{-1} \mathrm{~K}^{-1}$, and approx. $5.45 \mathrm{~W} \mathrm{~m}^{-1} \mathrm{~K}^{-1}$, respectively). These results show that the use of BNNS/[bmim] $\left[\mathrm{PF}_{6}\right]$ complexes is extremely effective to improve the throughplane TC of the BNNS/TP polymer composites. The throughplane TC is also superior to those of previously reported BNNS/TP polymer composites with similar BNNS loadings (around $50 \mathrm{wt} \%)^{34,35,37}$ (Table S1†). Increasing the thermal 
conductivity of BNNS/polymer composites with relatively lower BNNS loadings ( $\leq 50 \mathrm{wt} \%$ ) is crucially important for maintaining the mechanical properties, low density and good processability towards various applications.

2a/PC and 2a/PBT composite films were also prepared using the same method except for using HFIP instead of acetone (Fig. 9a and b). During the process of preparing the $2 \mathrm{a} / \mathrm{PC}$ composite films, 2a was not evenly dispersed in PC/HFIP solutions, giving uneven dispersion of BNNSs in $\mathbf{2 a} / \mathrm{PC}$ composites (Fig. 9a). The films were also much more brittle than the films of 2a/PMMA composites because of the worse compatibility of $[\mathrm{bmim}]\left[\mathrm{PF}_{6}\right]$ with PC than with PMMA. Imidazolium-based ILs reportedly show much poorer compatibility with PC than with PMMA. ${ }^{53}$ Actually, the 2a/PBT composite film was not brittle; it showed good surface appearance with uniform BNNS dispersion (Fig. 9b). The BNNSs were randomly oriented in the PBT matrix (Fig. 9c), although some apparently recoagulated during the process. The $\mathrm{BNNS} /[\mathrm{bmim}]\left[\mathrm{PF}_{6}\right]$ complexes were covered with PBT and were firmly embedded in the PBT matrix (Fig. 9c), indicating strong interactions between $\mathrm{BNNS} /[\mathrm{bmim}]\left[\mathrm{PF}_{6}\right]$ complexes and PBT. The through-plane TC of the 2a/PBT composite films containing $50 \mathrm{wt} \%$ of BNNS reached $\sim 5.77 \mathrm{~W}$ $\mathrm{m}^{-1} \mathrm{~K}^{-1}$ (Fig. 9d); the in-plane TC was $\sim 7.67 \mathrm{~W} \mathrm{~m}^{-1} \mathrm{~K}^{-1}$. Formation of the thermal-conductive paths because of the random orientation of BNNS throughout the whole composites and strong interactions between $\mathrm{BNNS} /[\mathrm{bmim}]\left[\mathrm{PF}_{6}\right]$ and $\mathrm{PBT}$
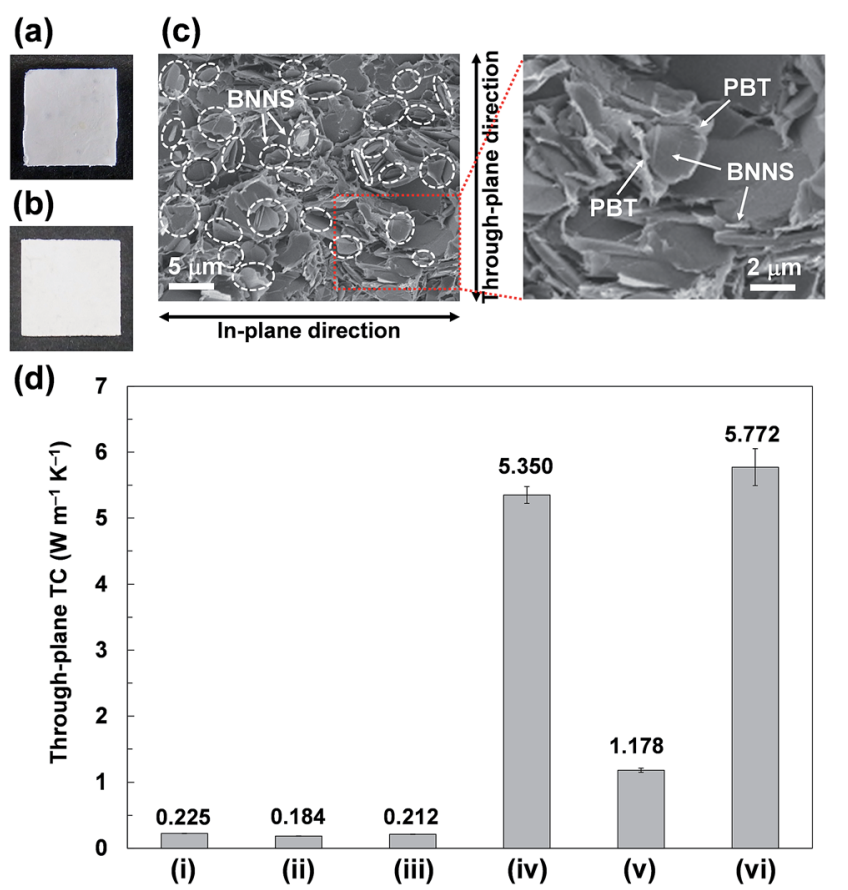

Fig. 9 Photographs of (a) 2a/PC composite film containing $50 \mathrm{wt} \%$ of BNNS and (b) 2a/PBT composite film containing $50 \mathrm{wt} \%$ of BNNS. Each film has approx. $0.3 \mathrm{~mm}$ thickness. (c) SEM image of frozen fracture surface of the 2a/PBT composite film containing $50 \mathrm{wt} \%$ of BNNS. Some BNNSs are surrounded by the white dotted-line circles in the figure. (d) Through-plane TCs of films of (i) PMMA, (ii) PC, (iii) PBT, (iv) 2a/PMMA composites, (v) 2a/PC composites, and (vi) 2a/PBT composites. Each $2 a / T P$ polymer composite contains $50 w t \%$ of BNNS. led to high through-plane and in-plane TCs. In addition, the through-plane $\mathrm{TC}$ of the $\mathrm{BNNS} /[\mathrm{bmim}]\left[\mathrm{PF}_{6}\right] / \mathrm{PBT}$ composite films was higher than that of $\mathrm{BNNS} /[\mathrm{bmim}]\left[\mathrm{PF}_{6}\right] / \mathrm{PMMA}$ composite films $\left(\sim 5.35 \mathrm{~W} \mathrm{~m}^{-1} \mathrm{~K}^{-1}\right)$, although the throughplane $\mathrm{TC}$ of the $\mathrm{BNNS} /[\mathrm{bmim}]\left[\mathrm{PF}_{6}\right] / \mathrm{PC}$ composite films containing $50 \mathrm{wt} \%$ of BNNS was extremely low $\left(\sim 1.18 \mathrm{~W} \mathrm{~m}^{-1} \mathrm{~K}^{-1}\right)$ (Fig. 9d). The surface tensions of PBT, PMMA, and PC are reported respectively as $\sim 42.4 \mathrm{~mJ} \mathrm{~m}^{-2}$ (at $313 \mathrm{~K}$ ), $\sim 40.9 \mathrm{~mJ} \mathrm{~m}^{-2}$ (at $343.2-383.2 \mathrm{~K}$ ), and $\sim 33.7 \mathrm{~mJ} \mathrm{~m}^{-2}$ (at $313 \mathrm{~K}$ ). ${ }^{54}$ The surface tension of $[\mathrm{bmim}]\left[\mathrm{PF}_{6}\right]$ is $\sim 49 \mathrm{~mJ} \mathrm{~m}^{-2}$ (at $298 \mathrm{~K}$ ), ${ }^{55}$ which closely matches the PBT surface tension. Therefore, the matching of their surface tensions is regarded as important for improving their affinity, leading to enhanced TC of the composites. Actually, the surface tension also played an important role to increase the solubility of BNNS/IL complex in organic solvent. $\mathrm{BNNS} /[\mathrm{bmim}]\left[\mathrm{PF}_{6}\right]$ were well dispersed in $N$-methyl-2pyrrolidone (NMP), but they were insufficiently dispersed in dimethylformamide (DMF) (Fig. S5 $\dagger$ ). The surface tension value of $[\mathrm{bmim}]\left[\mathrm{PF}_{6}\right]\left(\sim 49 \mathrm{~mJ} \mathrm{~m}^{-2}\right)$ is closer to that of NMP $(\sim 40 \mathrm{~mJ}$ $\left.\mathrm{m}^{-2}\right)^{56}$ than to that of DMF $\left(\sim 36 \mathrm{~mJ} \mathrm{~m}^{-2}\right) \cdot{ }^{57}$ The BNNS/[bmim] $\left[\mathrm{Tf}_{2} \mathrm{~N}\right]$ complexes (surface tension of $[\mathrm{bmim}]\left[\mathrm{Tf}_{2} \mathrm{~N}\right], \sim 33 \mathrm{~mJ}$ $\left.\mathrm{m}^{-2}\right)^{55}$ were well dispersed in DMF, suggesting that selecting IL species is extremely important to achieve good dispersion in both organic solvents and polymers.

In addition, volume resistivity of 2a/PMMA composite films was evaluated. Results showed that the volume resistivity of 2a/ PMMA composite films was higher than that of PMMA films (Fig. 10). Increasing BNNS content from $2 \mathrm{wt} \%$ to $24.5 \mathrm{wt} \%$ in 2a/PMMA composite films largely increased the volume resistivity (Fig. 10(v) and (vi)). The volume resistivity of 2a/PMMA composite films was also higher than that of h-BN/PMMA composite films with the same BNNS loadings (Fig. 10), which is probably due to an uneven dispersion of h-BNs in the PMMA matrix and weak interfaces between h-BNs and the matrix. In addition, volume resistivity of 2a/PBT composite films containing $50 \mathrm{wt} \%$ of BNNS was approx. $2.3 \times 10^{16} \Omega \mathrm{cm}$, which was also higher than PBT (approx. $3.7 \times 10^{15} \Omega \mathrm{cm}$ ) and h-BN/PBT $\left(50 \mathrm{wt} \% / 50 \mathrm{wt} \%\right.$ ) composites (approx. $1.0 \times 10^{16} \Omega \mathrm{cm}$ ). These

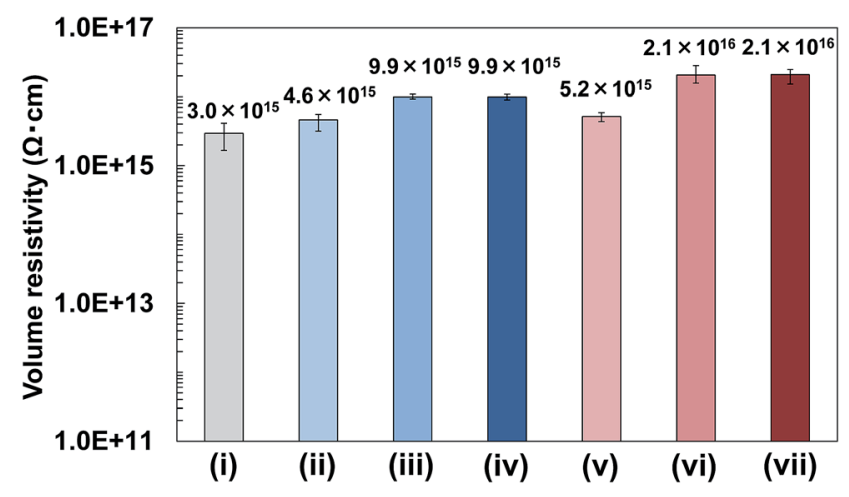

Fig. 10 Volume resistivity of films after a $1000 \mathrm{~V}$ potential was applied: (i) PMMA, (ii) h-BN/PMMA (2 wt\%/98 wt\%) composites, (iii) h-BN/PMMA (24.5 wt\%/75.5 wt\%) composites, (iv) h-BN/PMMA (50 wt\%/50 wt\%) composites, (v) 2a/PMMA composites containing 2 wt\% of BNNS, (vi) 2a/PMMA composites containing $24.5 \mathrm{wt} \%$ of BNNS, and (vii) 2a/PMMA composites containing $50 \mathrm{wt} \%$ of BNNS. 
results show that the use of $\mathrm{BNNS} /[\mathrm{bmim}]\left[\mathrm{PF}_{6}\right]$ complexes is very effective for improving the volume resistivity of TP polymers, although IL ([bmim $\left.]\left[\mathrm{PF}_{6}\right]\right)$ is not an electric insulator. Actually, the FR of BNNSs with [bmim] $\left[\mathrm{PF}_{6}\right]$ is small, and the electrical conductivity of $[\mathrm{bmim}]\left[\mathrm{PF}_{6}\right]$ itself is not high: ${ }^{58}$ much lower than traditional organic electrolytes. ${ }^{59}$ Moreover, electrically insulating BNNSs were dispersed uniformly in the matrix to increase the volume resistivity. Therefore, BNNS/[bmim] $\left[\mathrm{PF}_{6}\right] / \mathrm{TP}$ polymer composites enhanced both the TC and electrical insulation.

\section{Conclusions}

The use of ILs afforded not only high-yield, mild, facile exfoliation of h-BNs into few-layered BNNSs but also noncovalent functionalization of BNNSs for enhanced TCs of the BNNS/TP polymer composites. h-BNs were readily exfoliated into fewlayered BNNSs with micrometer-sized edges in $[\mathrm{bmim}]\left[\mathrm{PF}_{6}\right]$ in high yields after simple wet-exfoliation involving sonication, giving sufficient amounts of $\mathrm{BNNS} /[\mathrm{bmim}]\left[\mathrm{PF}_{6}\right]$ complexes for the fabrication and evaluation of $\mathrm{BNNS} /[\mathrm{bmim}]\left[\mathrm{PF}_{6}\right] / \mathrm{TP}$ polymer composites. BNNS/[bmim $]\left[\mathrm{PF}_{6}\right] / \mathrm{PMMA}$ composite films were prepared using a simple wet process. In the $\mathrm{BNNS} /[\mathrm{bmim}]$ $\left[\mathrm{PF}_{6}\right] / \mathrm{PMMA}$ composite films, BNNS were dispersed randomly in the PMMA matrix by physical adsorption with $[\mathrm{bmim}]\left[\mathrm{PF}_{6}\right]$ and a method using predispersed $\mathrm{BNNS} /[\mathrm{bmim}]\left[\mathrm{PF}_{6}\right] /$ acetone solutions. By mixing predispersed $\mathrm{BNNS} /[\mathrm{bmim}]\left[\mathrm{PF}_{6}\right] /$ acetone solutions with PMMA/acetone solutions, BNNSs were dispersed uniformly, even in the PMMA solutions with high viscosity. The through-plane and in-plane TCs for BNNS/[bmim] $\left[\mathrm{PF}_{6}\right] / \mathrm{PMMA}$ composite films containing $50 \mathrm{wt} \%(\approx 34 \mathrm{vol} \%)$ of BNNS with optimum FR value $(\sim 0.05)$ respectively reached $\sim 5.4 \mathrm{~W} \mathrm{~m}^{-1} \mathrm{~K}^{-1}$, and $\sim 7.3 \mathrm{~W} \mathrm{~m}^{-1} \mathrm{~K}^{-1}$. This through-plane TC is superior to that of h-BN/PMMA composites and those previously reported BNNS/TP polymer composites with similar BNNS loadings because of the randomly dispersed BNNSs and good affinity between PMMA and $\left[\mathrm{PF}_{6}\right]$ anions. Optimum FR was found for enhancing the TC of the composites because a large FR value also signifies an increase of the amounts of [bmim] $\left[\mathrm{PF}_{6}\right]$ with amorphous structure having low TC. The optimum represents a balance of an increased effect of compatibility of BNNS surfaces with the polymer matrix and a decreased effect of TC because of increased amorphous [bmim] $\left[\mathrm{PF}_{6}\right]$. The existence of an appropriate amount of $[\mathrm{bmim}]\left[\mathrm{PF}_{6}\right]$ at the interface is crucially important, but the combination of IL and polymer matrix species is also important. The through-plane TC of $\mathrm{BNNS} /[\mathrm{bmim}]\left[\mathrm{PF}_{6}\right] / \mathrm{PBT}$ composite films containing $50 \mathrm{wt} \%$ of BNNS with optimum $\mathrm{FR}$ value reached $\sim 5.8 \mathrm{~W} \mathrm{~m}^{-1} \mathrm{~K}^{-1}$, whereas that of $\mathrm{BNNS} /[\mathrm{bmim}]\left[\mathrm{PF}_{6}\right] / \mathrm{PC}$ composite films was $\sim 1.2 \mathrm{~W} \mathrm{~m}^{-1} \mathrm{~K}^{-1}$, which resulted from lower compatibility between $[\mathrm{bmim}]\left[\mathrm{PF}_{6}\right]$ and PC. Moreover, the BNNS/[bmim $]\left[\mathrm{PF}_{6}\right] /$ TP polymer composite films showed higher electrical insulation than pristine TP polymer and h-BN/TP polymer films. The highly thermally conductive and electrically insulating polymer nanocomposites based on BNNS/IL complexes are very promising for various applications such as next-generation power electronic devices, electric machinery, and communication equipment.

\section{Acknowledgements}

We are grateful to Yoshihide Katagiri, Dr Kenzo Fukumori, and Dr Hirotaka Okamoto for helpful discussions. We thank Yoshimi Muraoka for performing some SEM measurements. We also thank Noritomo Suzuki for some TEM observations.

\section{Notes and references}

1 R. Gao, L. Yin, C. Wang, Y. Qi, N. Lun, L. Zhang, Y.-X. Liu, L. Kang and X. Wang, J. Phys. Chem. C, 2009, 113, 15160.

2 Y. Lin and J. W. Connell, Nanoscale, 2012, 4, 6908.

3 Z. Wang, Z. Tang, Q. Xue, Y. Huang, Y. Huang, M. Zhu, Z. Pei, H. Li, H. Jiang, C. Fu and C. Zhi, Chem. Rec., 2016, 16, 1204. 4 L. Lindsay and D. A. Broido, Phys. Rev. B: Condens. Matter Mater. Phys., 2011, 84, 155421.

5 B. Mortazavi and G. Cuniberti, RSC Adv., 2014, 4, 19137.

6 N. Kostoglou, K. Polychronopoulou and C. Rebholz, Vacuum, 2015, 112, 42.

7 T. Morishita, M. Matsushita, Y. Katagiri and K. Fukumori, J. Mater. Chem., 2011, 21, 5610.

8 T. Morishita, Y. Katagiri, T. Matsunaga, Y. Muraoka and K. Fukumori, Compos. Sci. Technol., 2017, 142, 41.

9 A. A. Balandin, Nat. Mater., 2011, 10, 569.

10 T. Morishita, M. Matsushita, Y. Katagiri and K. Fukumori, Carbon, 2010, 48, 2308.

11 M. Shtein, R. Nadiv, M. Buzaglo, K. Kahil and O. Regev, Chem. Mater., 2015, 27, 2100.

12 Z. Spitalsky, D. Tasis, K. Papageli and C. Galiotis, Prog. Polym. Sci., 2010, 35, 357.

13 L. Song, L. Ci, H. Lu, P. B. Sorokin, C. Jin, J. Ni, A. G. Kvashnin, D. G. Kvashnin, J. Lou, B. I. Yakobson and P. M. Ajayan, Nano Lett., 2010, 10, 3209.

14 K. K. Kim, A. Hsu, X. Jia, S. M. Kim, Y. Shi, M. Hofman, D. Nezich, J. F. Rodriguez-Nieva, M. Dresselhaus, T. Palacios and J. Kong, Nano Lett., 2012, 12, 161.

15 C. Zhi, Y. Bando, C. Tang, H. Kuwahara and D. Golberg, Adv. Mater., 2009, 21, 2889.

16 J. N. Coleman, M. Lotya, A. O'Neill, S. D. Bergin, P. J. King, U. Khan, K. Young, A. Gaucher, S. De, R. J. Smith, I. V. Shvets, S. K. Arora, G. Stanton, H. Kim, K. Lee, G. T. Kim, G. S. Duesberg, T. Hallam, J. J. Boland, J. J. Wang, J. F. Donegan, J. C. Grunlan, G. Moriarty, A. Shmeliov, R. J. Nicholls, J. M. Perkins, E. M. Grieveson, K. Theuwissen, D. W. McComb, P. D. Nellist and V. Nicolosi, Science, 2011, 331, 568.

17 H. Tao, Y. Zhang, Y. Gao, Z. Sun, C. Yan and J. Texter, Phys. Chem. Chem. Phys., 2017, 19, 921.

18 W. Sun, Y. Meng, Q. Fu, F. Wang, G. Wang, W. Gao, X. Huang and F. Lu, ACS Appl. Mater. Interfaces, 2016, 8, 9881.

19 T. Morishita and H. Okamoto, ACS Appl. Mater. Interfaces, 2016, 8, 27064.

20 A. M. Joseph, B. Nagendra, E. Bhoje Gowd and K. P. Surendran, ACS Omega, 2016, 1, 1220. 
21 Y. Hernandez, V. Nicolosi, M. Lotya, F. M. Blighe, Z. Sun, S. De, I. T. McGovern, B. Holland, M. Byrne, Y. K. Gun'ko, J. J. Boland, P. Niraj, G. Duesberg, S. Krishnamurthy, R. Goodhue, J. Hutchison, V. Scardaci, A. C. Ferrari and J. N. Coleman, Nat. Nanotechnol., 2008, 3, 563.

22 U. Khan, A. O'Neill, M. Lotya, S. De and J. N. Coleman, Small, 2010, 6, 864 .

23 T. Morishita, A. J. Clancy and M. S. P. Shaffer, J. Mater. Chem. A, 2014, 2, 15022.

24 H. S. Leese, L. Govada, E. Saridakis, S. Khurshid, R. Menzel, T. Morishita, A. J. Clancy, E. R. White, N. E. Chayen and M. S. P. Shaffer, Chem. Sci., 2016, 7, 2916.

25 T. Morishita, H. Okamoto, Y. Katagiri, M. Matsushita and K. Fukumori, Chem. Commun., 2015, 51, 12068.

26 H. M. El-Dessouky and C. A. Lawrence, Composites, Part B, 2013, 50, 91.

27 W.-L. Song, P. Wang, L. Cao, A. Anderson, M. J. Meziani, A. J. Farr and Y.-P. Sun, Angew. Chem., Int. Ed., 2012, 51, 6498.

28 M.-H. Tsai, I.-H. Tseng, J.-C. Chiang and J.-J. Li, ACS Appl. Mater. Interfaces, 2014, 6, 8639.

29 K. Kim, M. Kim and J. Kim, Compos. Sci. Technol., 2014, 103, 72.

30 X.-B. Wang, Q. Weng, X. Wang, X. Li, J. Zhang, F. Liu, X.-F. Jiang, H. Guo, N. Xu, D. Golberg and Y. Bando, ACS Nano, 2014, 8, 9081.

31 J. Yu, H. Mo and P. Jiang, Polym. Adv. Technol., 2015, 26, 514.

32 Y. Xue, X. Jin, Y. Fan, R. Tian, X. Xu, J. Li, J. Zhang, L. Hu and C. Tang, Polym. Compos., 2014, 35, 1707.

33 J. Hou, G. Lia, N. Yang, L. Qin, M. E. Grami, Q. Zhang, N. Wang and X. Qu, RSC Adv., 2014, 4, 44282.

34 R.-C. Zhang, D. Sun, A. Liu, S. Askari, M. Macias-Montero, P. Joseph, D. Dixon, K. Ostrikov, P. Maguire and D. Mariotti, ACS Appl. Mater. Interfaces, 2016, 8, 13567.

35 S. Zhang, G. Lian, H. Si, J. Wang, X. Zhang, Q. Wang and D. Cui, J. Mater. Chem. A, 2013, 1, 5105.

36 X. Huang, S. Wang, M. Zhu, K. Yang, P. Jiang, Y. Bando, D. Golberg and C. Zhi, Nanotechnology, 2015, 26, 015705.

37 S. Li, T. Yang, H. Zou, M. Liang and Y. Chen, High Perform. Polym., 2017, 29, 315.

38 T. Sainsbury, A. Satti, P. May, Z. Wang, I. McGovern, Y. K. Gun'ko and J. Coleman, J. Am. Chem. Soc., 2012, 134, 18758.
39 Q. Weng, X. Wang, X. Wang, Y. Bando and D. Golberg, Chem. Soc. Rev., 2016, 45, 3989.

40 T. Morishita, M. Matsushita, Y. Katagiri and K. Fukumori, Carbon, 2009, 47, 2716.

41 T. Morishita, M. Matsushita, Y. Katagiri and K. Fukumori, Carbon, 2011, 49, 5185.

42 J. A. Mann and W. R. Dichtel, J. Phys. Chem. Lett., 2013, 4, 2649.

43 M. Du, Y. Wu and X. Hao, CrystEngComm, 2013, 15, 1782.

44 Y. Xue, Q. Liu, G. He, K. Xu, L. Jiang, X. $\mathrm{Hu}$ and J. $\mathrm{Hu}$, Nanoscale Res. Lett., 2013, 8, 49.

45 J. D. Oxley, T. Prozorov and K. S. Suslick, J. Am. Chem. Soc., 2003, 125, 11138.

46 E. B. Flint and K. S. Suslick, Science, 1991, 253, 1397.

47 M. Shakourian-Fard, G. Kamath and Z. Jamshidi, J. Phys. Chem. C, 2014, 118, 26003.

48 D. Ensling, M. Stjerndahl, A. Nytén, T. Gustafsson and J. O. A. Thomas, J. Mater. Chem., 2009, 19, 82.

49 X. Liu, J. Pu, L. Wang and Q. Xue, J. Mater. Chem. A, 2013, 1, 3797.

50 Y. M. Shul'ga, A. V. Bulatov, R. A. T. Gould, W. V. Konze and L. H. Pignolet, Inorg. Chem., 1992, 31, 4704.

51 K. Ueno, T. Fukai, T. Nagatsuka, T. Yasuda and M. Watanabe, Langmuir, 2014, 30, 3228.

52 L. Zhao, Y. Li, X. Cao, J. You and W. Dong, Nanotechnology, 2012, 23, 255702.

53 F. J. Carrión, C. Espejo, J. Sanes and M. D. Bermúdez, Compos. Sci. Technol., 2010, 70, 2160.

54 J. M. R. C. A. Santos, K. Fagelman and J. T. Guthrie, J. Chromatogr. A, 2002, 969, 119.

55 M. Tariq, M. G. Freire, B. Saramago, J. A. P. Coutinho, J. N. C. Lopes and L. P. N. Rebelo, Chem. Soc. Rev., 2012, 41, 829.

56 S. D. Bergin, V. Nicolosi, P. V. Streich, S. Giordani, Z. Sun, A. H. Windle, P. Ryan, N. P. P. Niraj, Z.-T. T. Wang, L. Carpenter, W. J. Blau, J. J. Boland, J. P. Hamilton and J. N. Coleman, Adv. Mater., 2008, 20, 1876.

57 H. Kahl, T. Wadewitz and J. Winkelmann, J. Chem. Eng. Data, 2003, 48, 580.

58 O. Zech, A. Stoppa, R. Buchner and W. Kunz, J. Chem. Eng. Data, 2010, 55, 1774.

59 Q.-G. Zhang, S.-S. Sun, S. Pitula, Q.-S. Liu, U. Welz-Biermann and J.-J. Zhang, J. Chem. Eng. Data, 2011, 56, 4659. 